\title{
Revealing social-ecological systems trajectories to enhance their sustainability
}

\author{
Fabien Arnaud ${ }^{1}$, J. Dearing ${ }^{2}$, P. Gell ${ }^{3}$, K. Walsh ${ }^{4}$ and D. Penny ${ }^{5}$ \\ Chambéry, France, 30 May - 1 June 2016
}

Paleosciences played a crucial role in the societal acknowledgement of humankind's responsibility for global warming. However, while the Earth is simultaneously facing its sixth mass extinction, mainly triggered by human activities and a dramatic rise in human population, it appears more and more obvious that climate is not the sole human-modified system whose dysfunction threatens the security and well-being of humans. Biodiversity loss, soil degradation, the spreading of contaminants, and disturbed nutrient cycles are of particular concern (Steffen et al. 2015). The long-term dynamics of those threats to ecosystems, as well as their impact on ecosystem services, remain largely unknown.

Understanding the complex long-term interactions between human actions, climate and the functioning of social-ecological systems is critical to prepare a safe future (Costanza et al. 2007; Dearing et al. 2015). Addressing these interactions also contributes to the Future Earth Vision 2025 call for new integrated scientific approaches to better understand the complex dynamics of social-ecological systems. In this context, this workshop investigated the potential of paleosciences to create knowledge to help increase the sustainability of human development on Earth.

\section{Scientific contributions and discussions}

The workshop was split into three parts with the aim of answering the questions: (1) why, (2) what kind and (3) how to integrate paleodata to better understand complex human-climate-environment interactions? Based on case studies, conceptual advancements were presented. In particular, the attendees debated the interest of transposing the concepts of "safe operating space" and "ecosystem services" to paleostudies. Those concepts could indeed permit the description of the evolution of the environment from a societal point of view with a limited number of descriptors. This point appeared crucial, considering the great diversity of reconstructed variables. Such an approach could provide the foundation for the integration of various proxies from a large variety of disciplines (Fig. 1).

Among the innovative proxies of past changes, DNA and chemical biomarkers appear particularly promising. The integration of archeological and paleoenvironmental data to explain civilization collapses or landscape shaping is of
Multiproxies paleoenvironmental record

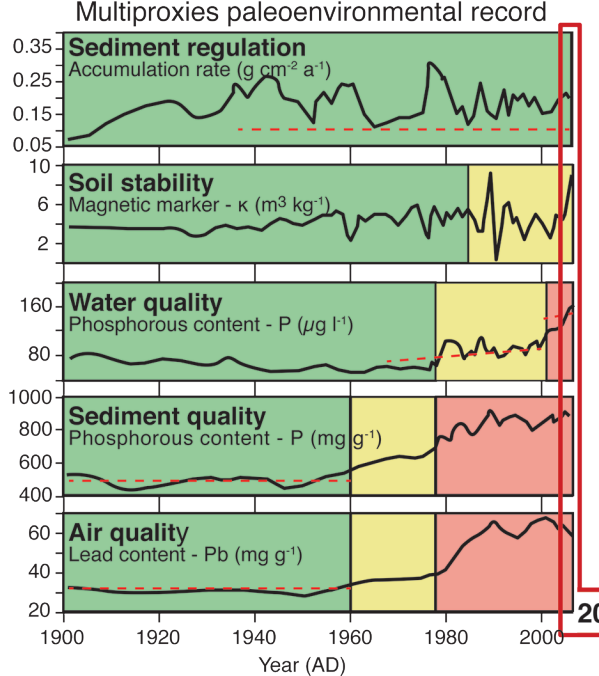

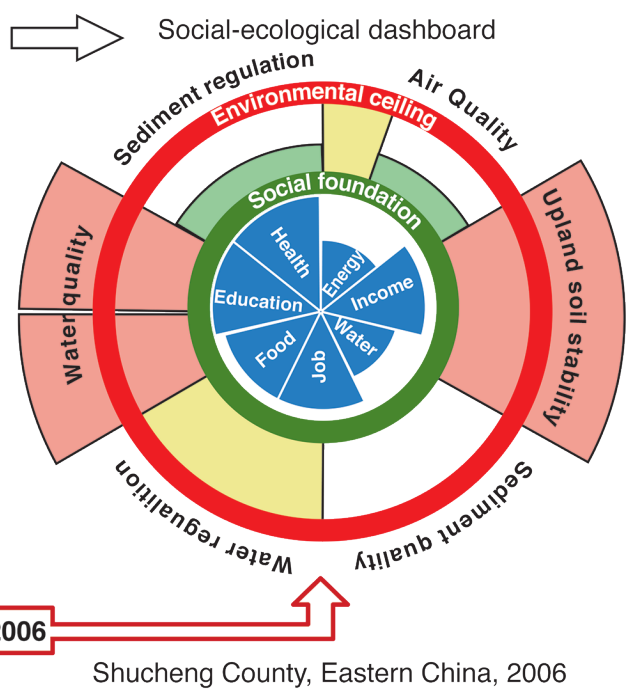

Figure 1: Combination of paleoecological proxies to propose an evaluation of ecosystem functioning and threats of a given region, taking account of its social-ecological trajectories - here for Shuncheng County, China (modified from Dearing et al. 2014). Such an approach combines the concepts of paleo-ecosystem services (Dearing et al. 2012) and safe operating space for humanity (Raworth 2012; Rockström et al. 2009

particular interest, but better information systems that combine both the spatial and temporal aspects still need to be developed. Finally, while the ability of models to depict societal-environmental dynamics is getting better, they are still rarely used. Especially at a regional scale, models could be used to connect the local contribution of human practices to global changes and human vulnerability.

\section{Working group perspective}

The workshop assembled a new scientific community and generated fruitful and novel discussions. Attendees agreed to submit a proposal for the creation of a new PAGES working group titled "Socialenvironmental trajectories". The aim of this group would be to promote the development of a scientific community located at the junction of the paleo-, ecological- and human sciences. Based both on proxy reconstructions and ecosystem services-oriented modeling, this group seeks to understand how human practices in the past were successful in the face of global changes over long time periods. Hence the group would ultimately question the resilience of today's societies in the face of global changes, with respect to cultural and natural heritage in particular.

\section{AFFILIATIONS}

'Environment Dynamics and Territories of Mountains (CNRS), University Savoie Mont Blanc, Chambéry, France

2Palaeoecology Laboratory, Geography and Environment, University of Southampton, UK ${ }^{3}$ Water Research Network, Federation University, Ballarat, Australia

${ }^{4}$ Department of Archaeology, University of York, UK ${ }^{5}$ Faculty of science, University of Sydney, Australia

\section{CONTACT}

Fabien Arnaud: fabien.arnaud@univ-smb.fr

\section{REFERENCES}

Costanza R et al. (2007) Ambio 36: 522-527

Dearing JA et al. (2015) Anthrop Rev 2: 220-246

Dearing JA et al. (2014) Glob Environ Change 28: 227-238 Dearing JA et al. (2012) PNAS 109: E1111-E1120

Raworth K (2012) A Safe and Just Space for Humanity Oxfam Discuss Pap

Rockström J et al. (2009) Nature 461: 472-475

Steffen W. et al. (2015) Science 347: 736 